\title{
A FORMAÇÃO INICIAL EM QUÍMICA BASEADA EM CONCEITOS REPRESENTADOS POR MEIO DE MODELOS MENTAIS
}

\author{
Gustavo Bizarria Gibin* e Luiz Henrique Ferreira \\ Departamento de Química, Universidade Federal de São Carlos, CP 676, 13560-970 São Carlos - SP, Brasil
}

Recebido em 4/1/10; aceito em 15/4/10; publicado na web em 9/8/10

\begin{abstract}
CHEMISTRY EDUCATION BASED ON CONCEPTS REPRESENTED BY MENTAL MODELS. The current legislation determines that the chemist must have a solid comprehension about chemical concepts. Literature presents the concept of mental model, which is determinant to the learning of phenomena and concepts. This paper presents some mental models that students of the Chemistry course at UFSCar have about chemical concepts. A lot of incoherence was observed in student's mental models, which is an evidence that there are problems in the learning of chemistry education.
\end{abstract}

Keywords: chemistry education; mental models; images.

\section{INTRODUÇÃO}

De acordo com a Lei de Diretrizes e Bases da Educação Nacional, a Educação Superior deve formar pessoas reflexivas, aptas para inserir-se em diferentes setores profissionais e para contribuir com o desenvolvimento da sociedade brasileira. ${ }^{1}$ Neste contexto, é fundamental que os futuros profissionais da Química adquiram uma formação sólida e estejam preparados para empregar seu conhecimento nas mais variadas situações.

Os professores do Ensino Superior brasileiro, tanto de universidades públicas quanto de particulares, geralmente utilizam o modelo tradicional de ensino que ocorre por meio do processo de transmissãorecepção de informações. Nesse modelo, o professor tem a função de transmitir os conhecimentos que deverão ser guardados pelos alunos, considerados "tábulas rasas", isto é, mentes vazias que devem ser preenchidas gradualmente com essas informações. ${ }^{2}$

Em geral, o modelo tradicional de ensino ignora os conhecimentos prévios dos alunos, diferentemente do que propõem os construtivistas, ${ }^{3}$ que consideram a aprendizagem como uma conexão das novas informações com os conhecimentos prévios, daí sua elevada importância. Nesta visão, o ensino deveria partir das concepções dos alunos e da sua realidade. Além disso, o que se observa na abordagem tradicional, é que os conteúdos são apresentados em um contexto não significativo, ou seja, muito distantes de qualquer aplicação prática, dificultando o relacionamento entre o conhecimento adquirido e sua respectiva utilização externa ao ambiente escolar.

Tais aspectos devem ser levados em conta durante a formação inicial dos estudantes em nível de Ensino Superior, visando uma contribuição para a aprendizagem de conceitos e, principalmente, para a formação de cidadãos.

\section{A FORMAÇÃO INICIAL EM QUÍMICA}

De acordo com as Diretrizes Curriculares Nacionais para os Cursos de Química, espera-se que o químico, bacharel ou licenciado, desenvolva as seguintes habilidades em relação à compreensão da Química: ${ }^{4}$ a) compreender os principais conceitos, leis e princípios da Química; b) conhecer as propriedades físicas e químicas principais dos elementos e compostos, que possibilitem entender e prever o seu comportamento físico-químico, aspectos de reatividade, mecanismos

\footnotetext{
*e-mail: gustavogibin@yahoo.com.br
}

e estabilidade; c) reconhecer a Química como uma construção humana e compreender os aspectos históricos de sua produção e suas relações com o contexto cultural, socioeconômico e político.

Dessa forma, o químico deve ter uma compreensão sólida acerca dos conceitos químicos, para entender, explicar e prever o comportamento de sistemas químicos. Além disso, é importante para a sua formação compreender a natureza da Ciência e suas interrelações com a sociedade e a tecnologia.

Centrando-se na questão do conhecimento químico que o profissional deve possuir, independentemente da habilitação em que seu curso se enquadra, a literatura apresenta as seguintes subáreas: ${ }^{5,6}$ tópicos de Química, iniciação à Química experimental, Química Analítica, FísicoQuímica, Química Orgânica, Química Inorgânica e Bioquímica. Os conteúdos de cada subárea do conhecimento químico serão expostos de forma resumida a seguir: estrutura atômica; periodicidade química; ligações químicas; forças intermoleculares; ácidos e bases; planejamento experimental (quimiometria); equilíbrios de íons em solução; metodologias de análise química (amostragem, tratamento da amostra, avaliação e interpretação de resultados analíticos); análise qualitativa e quantitativa (volumetria, gravimetria, métodos eletroanalíticos, espectroscópicos, por exemplo, UV/VIS, IV, RNM, análise térmica, cromatografia e eletroforese); teoria cinética e gases reais; termodinâmica e termoquímica; mudanças de estado (potencial químico, misturas binárias e ternárias); propriedades coligativas; cinética química e catálise; eletroquímica; elementos e compostos químicos (ocorrência, propriedades, obtenção e aplicações); sólidos (parâmetros reticulares, estrutura cristalina); compostos de coordenação, organometálicos, macro e biomoléculas; mecanismos de reação; operações básicas de laboratório como preparação e caracterização de substâncias.

Assim, espera-se que um químico apresente o domínio vasto de conteúdos, tanto de natureza conceitual quanto procedimental e o acréscimo de outros conteúdos é que caracterizarão a habilitação (Bacharelado ou Licenciatura) do curso de Química. Dessa forma, é possível refletir se os cursos de formação inicial em Química têm proporcionado o aprendizado necessário de tais conceitos químicos. Outra reflexão possível é se a carga horária elevada de disciplinas de Química é condição necessária e suficiente ao aprendizado de todos esses conceitos fundamentais apresentados anteriormente.

As avaliações do Exame Nacional de Cursos - ENC - (Provão) e o ENADE de 2000 a 2005 apontam que existem problemas na formação inicial de profissionais da Química. A média obtida pelos estudantes que prestaram estes exames, com exceção de 2000, é praticamente 
idêntica, o que demonstra ausência de crescimento no desempenho. Além disso, a média 36 a 37 (de um total de 100 pontos) é muito baixa. Assim, essas médias fornecem um indício importante de problemas na formação dos profissionais da Química. ${ }^{7}$

Dessa forma, torna-se importante entender como ocorre a compreensão dos conceitos químicos pelos estudantes, compreensão esta para a qual a teoria dos modelos mentais, referencial empregado neste estudo, pode contribuir.

\section{A TEORIA DOS MODELOS MENTAIS}

Em Ciências, os modelos desempenham um papel central. Os modelos estão no centro de qualquer teoria: são as ferramentas usadas pelos cientistas para produzir conhecimento e um dos principais produtos da ciência. ${ }^{8}$ Kuhn aponta que os modelos auxiliam na determinação do que é aceito como explicação para um fenômeno ou a solução de um quebra-cabeça. ${ }^{9}$ Assim, os modelos ajudam a determinar qual é a lista de quebra-cabeças não solucionados por uma teoria e a avaliar a importância deles.

Um modelo pode ser definido como uma representação de um objeto, evento, processo ou ideia, que possui objetivos específicos como facilitar a visualização; fundamentar a elaboração e o teste de novas ideias; possibilitar a elaboração de explicações e previsões sobre o comportamento e as propriedades de um sistema em estudo. ${ }^{8}$ Portanto, um modelo é uma forma de representação da realidade produzida por meio das interpretações pessoais entre o cientista e o sistema estudado.

O uso de modelos é importante para o desenvolvimento da Ciência e, além disso, é parte integral do processo de aquisição de conhecimento pelo ser humano. O processo de construção de uma explicação para um fenômeno é semelhante entre cientistas e leigos, mas com graus de complexidade e rigor diferentes. Modelos são criados e utilizados por cientistas e por leigos para explicar fenômenos de interesse.

Johnson-Laird propõe uma teoria em relação ao processo de aquisição de conhecimento pelo ser humano, segundo a qual existem três tipos básicos de elaboração de explicações para fenômenos: representações proposicionais, imagens e modelos mentais. ${ }^{10}$ Representações proposicionais são cadeias de símbolos que correspondem à linguagem natural, modelos mentais são análogos estruturais do mundo e imagens são visualizações de modelos sob um determinado ponto de vista. Essa teoria foi um marco para a psicologia cognitiva e, por isso, representa o principal referencial teórico neste trabalho de pesquisa aqui descrito.

Assim, segundo a teoria proposta, as pessoas raciocinam em termos de modelos mentais. Logo, a linguagem mental processa uma representação proposicional em termos de modelos mentais. Então, as proposições podem ser consideradas como formas de "entrada" e, dessa forma, proporcionam a elaboração do modelo mental. Os modelos mentais, assim como as imagens, são altamente específicos e esta propriedade os diferencia das representações proposicionais. Além disso, as imagens são definidas como formas de visualização dos modelos mentais de acordo com a teoria elaborada por Johnson-Laird. ${ }^{10}$

Johnson-Laird define modelos mentais como formas de representação interna de informações, conceitos ou fenômenos que correspondem a determinados eventos. ${ }^{10}$ Borges aponta que os " $m o$ delos mentais são usados para caracterizar as formas pelas quais as pessoas compreendem os sistemas físicos com os quais interagem". ${ }^{11}$ Portanto, na compreensão de conceitos químicos, os modelos mentais apresentam um papel central. Os modelos mentais são as estruturas cognitivas internas das pessoas, que correspondem ao modo como as pessoas compreendem os fenômenos químicos.

As principais características dos modelos mentais são: são incompletos - geralmente as pessoas possuem a habilidade de "executar" seus modelos mentais de forma muito limitada; são instáveis - as pessoas esquecem detalhes do modelo; não têm fronteiras bem defi- nidas - operações e conceitos semelhantes são confundidos; são "não científicos" - as pessoas mantêm padrões de comportamento "supersticiosos", mesmo quando sabem que não são necessários, assim, os modelos mentais de uma pessoa refletem suas crenças sobre o sistema em estudo e, por fim, são econômicos - os modelos elaborados tendem a ser o mais simples possível. ${ }^{12}$ Dessa forma, em investigações sobre modelos mentais é importante esperar que os modelos apresentados possam ser equivocados, ambíguos e incompletos.

O sistema que é o objeto de algum estudo é denominado sistema alvo. Assim, um modelo conceitual é construído com a finalidade de representar de forma adequada o sistema alvo, no sentido de ser uma representação precisa, consistente, coerente e completa. Portanto, modelos conceituais são elaborados por professores, projetistas, cientistas com a finalidade de explicar de forma coerente um sistema físico. Logo, os modelos conceituais devem ser funcionais, de fácil uso e compreensão. ${ }^{12}$ Então, considera-se um modelo conceitual como aquele aceito pela comunidade científica sobre determinado assunto e que o professor deve ter domínio ao planejar suas atividades didáticas.

De modo geral, em relação à tipologia, os modelos mentais podem ser divididos em dois grandes grupos: os físicos e os conceituais. Modelos físicos representam o mundo físico enquanto modelos conceituais representam conceitos abstratos, como silogismos, por exemplo. Dentre os modelos físicos, existem seis tipos: ${ }^{10}$

Modelo relacional: é um 'quadro' estático que possui vários elementos, que apresentam características e propriedades que representam as propriedades e características da entidade real. Além disso, também apresenta as relações entre os elementos, que existem entre as entidades reais. Por exemplo, o quadro Mona lisa, de Leonardo da Vinci, pode ser descrito, com todos os seus elementos e propriedades, para que seja possível a construção de um modelo mental relacional sobre esta obra.

Modelo espacial: é em um modelo relacional em que a única relação existente entre os elementos é de natureza espacial.

Modelo temporal: consiste em uma sequiência de 'quadros' de modelos espaciais, em que existe uma ordem temporal de ocorrência de eventos. O modelo temporal pode não possuir uma linearidade, assim como uma temporalidade contínua.

Modelo cinemático: é um modelo temporal que é psicologicamente contínuo. Os elementos apresentam mudanças de propriedades e movimentos de forma contínua e fluída. Pode ser considerado como um "filme" que é exibido na mente das pessoas.

Modelo dinâmico: é um modelo cinemático em que existem relações de causa e efeito entre alguns quadros.

Imagem: consiste em uma visualização do modelo elaborada pelo observador. A imagem expressa as características visíveis de um modelo espacial tridimensional ou de um modelo cinemático/dinâmico.

Ontoria, Luque e Gómez assinalam que na sociedade ocidental o pensamento é expresso basicamente por meio de palavras e que, além disso, a utilização de imagens para a elaboração de pensamentos é considerada como sinal de imaturidade cognitiva. ${ }^{13}$ Estes autores discordam desse senso comum em relação ao uso de imagens na estrutura cognitiva, e apontam que essa ideia é proveniente de um predomínio cultural baseado no uso de palavras. Além disso, os autores expõem os seguintes argumentos a favor do uso de imagens: ${ }^{13}$

"Havendo um predomínio visual no conhecimento, em termos gerais, a utilização de imagens visuais facilita e estimula a retenção e a lembrança do que foi aprendido. A imagem, portanto, ativa uma ampla variedade de habilidades no cérebro, como formas, cores, linhas, dimensões, etc., ou seja, habilidades que estimulam a imaginação, promovem o pensamento criativo e ajudam a memória, pois as imagens visuais são mais lembradas que as palavras" ${ }^{13}$ (p. 52-53). 
Assim, o uso das imagens promove uma série de efeitos benéficos e interessantes em relação à estrutura cognitiva dos estudantes. As grandes vantagens são o estímulo à memória e à criatividade, duas habilidades que são importantes e requisitadas atualmente tanto na educação quanto no mercado de trabalho. Portanto, a utilização de imagens é apropriada e deveria ser mais utilizada pelos professores.

\section{USO DE IMAGENS NO ENSINO DE QUÍMICA}

A compreensão do conhecimento químico envolve três diferentes níveis de representação: macroscópico, submicroscópico e simbólico. ${ }^{14,15} \mathrm{O}$ nível de representação macroscópico engloba todos os fenômenos que são observáveis como, por exemplo, experimentos e fotografias de sistemas químicos. No nível submicroscópico o fenômeno químico é representado por meio do arranjo espacial e pelo movimento/interação de moléculas, átomos, íons, elétrons ou outras espécies químicas. É importante salientar que este nível explica em termos atômicos/moleculares as representações macroscópicas. Além disso, cabe apontar que geralmente essas representações são apresentadas por meio de imagens, entretanto, o uso de imagens no ensino em todos os níveis é muito pequeno. O nível simbólico referese à linguagem empregada pelos químicos como, por exemplo, as representações simbólicas de átomos, moléculas, fórmulas, equações e estruturas. ${ }^{16}$ Dessa forma, é fundamental conhecer estes níveis de representação da Química, para obter uma boa compreensão conceitual. Além disso, é de suma importância aprender a transitar entre estes níveis de representação, pois assim se elaboram os modelos mentais sobre conceitos ou fenômenos químicos. ${ }^{17}$

Várias pesquisas mostram que os estudantes, de modo geral, possuem dificuldades para compreender os níveis de representações em Química. Os estudantes apresentam dificuldades principalmente em relação às representações submicroscópica e simbólica porque estas são abstratas, e o pensamento dos alunos é construído por meio do emprego de informações sensoriais. ${ }^{18}$ Além disso, os alunos não conseguem estabelecer relações adequadas entre o nível macroscópico e o submicroscópico. ${ }^{19}$ Assim, é interessante realizar investigações sobre as dificuldades apresentadas pelos alunos nas diferentes formas de representação do conhecimento químico, e como os estudantes elaboram seus modelos mentais sobre conceitos ou fenômenos químicos, para contribuir com a melhoria da aprendizagem científica em todos os níveis de ensino.

$\mathrm{O}$ uso da internet como ferramenta pedagógica alternativa no ensino de Química proporcionou um avanço no desenvolvimento de algumas habilidades dos estudantes de graduação em Química, como a compreensão das representações submicroscópica e simbólica e, além disso, proporcionou uma elevação significativa na motivação dos alunos. ${ }^{20}$ Oblinger propõe que: ${ }^{21}$ " $a$ interação entre estudantes, o professor e as aplicações multimídia faz com que os estudantes tornem-se participantes ativos no processo de aprendizagem". Ainda segundo a autora (p. 247):21

\begin{abstract}
"As instituições consideram a instrução multimídia mais eficiente por causa dos sentidos que são envolvidos durante o processo de aprendizagem. Se o professor fica na frente da sala e apenas fala com os alunos, eles irão reter somente cerca de $20 \%$ do que ouvem. Alunos que vêem e ouvem informações, podem reter cerca de $40 \%$ da informação que é transmitida. Mas estudantes que vêem, ouvem e que estão ativamente envolvidos no processo de aprendizagem, retém aproximadamente $75 \%$ das informações".
\end{abstract}

Nesta direção, quando os estudantes estão envolvidos na situação de ensino - têm os seus sentidos empregados na atividade e são sujeitos ativos na construção de seus conhecimentos - ocorre uma tendência da aprendizagem vir a ser significativa. Além disso, existe um aumento considerável na retenção de conteúdos.

Um possível meio de proporcionar avanços na aprendizagem de conteúdos conceituais seria explorando o sentido da visão, através da utilização de imagens e/ou de animações. ${ }^{22-26}$ Por meio da utilização desses instrumentos didáticos, é possível proporcionar uma aprendizagem mais eficiente e interessante para os alunos.

$\mathrm{Na}$ atividade didática, o sensorial auxilia o aluno a organizar melhor as suas ideias e a integrá-las numa visão de totalidade. Dessa forma, o estudante parte da imagem "sensorial", mais imediata, e vai gradativamente evoluindo para a imagem "mental", que é uma representação menos dependente dos sentidos, mais elaborada, complexa. ${ }^{27}$ Assim, por meio da observação das imagens, o aluno estabelece relações e comparações, o que contribui para a elaboração de um modelo mental mais aprimorado.

O uso de visualizações pode ser muito interessante e útil para o ensino de Química, principalmente na forma de demonstrações na sala de aula e de animações que representem o nível submicroscópico. ${ }^{28}$ Estudos evidenciaram que o uso de animações que representam fenômenos em nível submicroscópico e demonstrações em vídeo tem proporcionado aos estudantes o desenvolvimento da habilidade de relacionar os níveis de representação simbólico, macroscópico e submicroscópico de forma adequada, além de melhorar a compreensão conceitual. ${ }^{29}$ Estas habilidades promovem o desenvolvimento da capacidade de elaboração de modelos mentais dinâmicos referentes a conceitos químicos.

Na Química, os modelos mentais são estabelecidos principalmente pela relação entre os níveis macroscópico e submicroscópico, pois o nível submicroscópico basicamente consiste em um modelo explicativo da natureza da matéria. As relações existentes entre os níveis simbólico e submicroscópico proporcionam pouco subsídio para a construção de modelos mentais, pois coeficientes estequiométricos e índices podem fornecer apenas dados quantitativos sobre um sistema. Já a relação entre o nível macroscópico e simbólico não fornece praticamente nenhum subsídio para a elaboração de modelos em relação a sistemas químicos.

Assim, no ensino de Química, ao tentar desenvolver nos estudantes a habilidade de construir modelos mentais sobre conceitos químicos, é interessante iniciar as atividades didáticas por meio da observação ou manipulação de algo concreto, no nível macroscópico, como a realização de um experimento, por exemplo. Em seguida, é importante trabalhar em nível submicroscópico, seja por meio do uso de imagens, animações, vídeos ou modelos moleculares para estimular os alunos a raciocinarem em nível submicroscópico e elaborar modelos mentais adequados sobre o sistema químico em estudo. Deve-se enfatizar que o nível simbólico é importante e que também deve ser trabalhado nas aulas, pois trata da linguagem empregada na Química. Entretanto, este nível não deve ser o único a ser ensinado, como ocorre no ensino tradicional, pois não auxilia na elaboração de modelos mentais sobre conceitos químicos.

O objetivo do trabalho foi avaliar a evolução dos modelos mentais sobre fenômenos químicos de estudantes de todos os períodos de um curso de Licenciatura e comparar os modelos dos formandos deste curso com os de formandos de um curso de Bacharelado em Química.

\section{METODOLOGIA}

Foi realizada uma investigação com alunos dos cursos de Química da Universidade Federal de São Carlos para a identificação de seus modelos mentais em relação a diversos fenômenos químicos. A coleta de dados foi realizada por meio da aplicação de um teste escrito. $\mathrm{O}$ teste elaborado apresentou somente questões objetivas contendo cinco alternativas com figuras representativas de conceitos químicos. Foi 
solicitado que se estabelecesse uma relação entre a imagem referente ao fenômeno/conceito químico e a alternativa correta.

O teste foi composto por 14 imagens referentes a conteúdos trabalhados durante os cursos de Química. Tentou-se formular 2 questões relacionadas às disciplinas de cada semestre dos cursos, considerando-se o fato de a Licenciatura ter duração de 10 semestres e o Bacharelado 8. Desta forma, foram selecionados conteúdos comuns aos dois cursos. As questões foram dispostas no teste na sequência em que os temas foram abordados nos cursos. Embora o teste não tenha sido validado antes da aplicação, as questões foram submetidas a uma avaliação crítica por parte de docentes de diferentes áreas, responsáveis por disciplinas de ambos os cursos e, posteriormente, aplicado em todas as turmas do curso de Licenciatura e apenas na turma de formandos do curso de Bacharelado.

\section{RESULTADOS E DISCUSSÃO}

De forma geral, pode-se afirmar que houve evolução nos modelos mentais dos estudantes de Licenciatura durante o curso. É possível observar as porcentagens de acerto referentes a cada turma na Tabela 1.

Tabela 1. Porcentagem de acerto no teste das turmas que participaram da pesquisa

\begin{tabular}{lc}
\hline Turma & $\%$ de acertos \\
\hline $1^{\circ}$ ano & 54,7 \\
$2^{\circ}$ ano & 59,3 \\
$3^{\circ}$ ano & 73,1 \\
$4^{\text {o }}$ ano & 70,8 \\
Formandos da Licenciatura & 72,5 \\
Formandos do Bacharelado & 55,6 \\
\hline
\end{tabular}

A evolução da aprendizagem ao longo do curso pode ser evidenciada pelo desempenho em questões envolvendo conceitos de precisão e exatidão em análise química, catálise heterogênea e choques de moléculas com orientações adequadas para a ocorrência de reação. É possível notar que os alunos foram melhorando seus modelos mentais em relação a alguns fenômenos e, dessa forma, houve aprendizagem sobre conceitos químicos. Porém, para os conceitos de combustão, equilíbrio químico, isomeria espacial, condutividade de uma solução, $1^{\text {a }}$ lei da termodinâmica e interações intermoleculares verificou-se uma diminuição do desempenho dos alunos, com o decorrer do curso. Isto fornece evidências que independente da área da Química, os estudantes não apresentaram modelos mentais coerentes para certos fenômenos e, dessa forma, dá indícios de que não houve aprendizagem sobre alguns conceitos químicos.

De acordo com a Tabela 1, houve um melhor aproveitamento dos formandos em Licenciatura, embora a carga horária de disciplinas de Química na grade curricular do curso de Bacharelado (1800 h) seja significativamente maior que a correspondente no curso de Licenciatura (900 h). Dessa forma, parece que um excesso de carga horária não representa aumento na aprendizagem de conceitos químicos, pelo contrário, a sobrecarga de disciplinas trabalhadas de maneira tradicional e, portanto, pouco reflexiva, não contribui efetivamente para o aprendizado e tampouco para a compreensão do que é pensar cientificamente. Além disso, Nardi e Longuini discutem que as atividades didáticas, como planejamento, aplicação e reflexão sobre a prática pedagógica, contribuem para o desenvolvimento do conhecimento químico. ${ }^{30}$

De forma geral, o teste mostrou que os alunos não apresentaram dificuldades em relacionar as imagens com os seguintes conceitos: interações intermoleculares, ionização de um ácido, complexo de coordenação, isomeria espacial e reação enzimática, ao contrário do que ocorre com os conceitos de equilíbrio químico, catálise heterogênea e choques orientados para ocorrência de reações químicas. Entretanto, observou-se que alguns conceitos foram problemáticos para os estudantes em geral. A seguir, serão apresentados os conceitos/fenômenos químicos em que os estudantes apresentaram as maiores dificuldades para relacionar uma possível representação de um fenômeno com a alternativa correspondente.

Em relação ao conceito de condutividade em solução iônica, 47\% dos estudantes também apresentaram modelos inadequados, pois não relacionaram corretamente conceito e imagem. A Figura 1 apresenta a questão e a ilustração empregada.

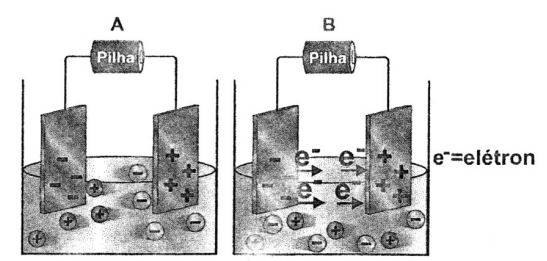

8) Qual figura melhor representa a condutividade de uma solução?

$\mathrm{A}-(\mathrm{)})$ apenas o sistema A.

$\mathrm{B}-($ ) apenas o sistema B.

$\mathrm{C}-($ ) ambos os sistemas.

$\mathrm{D}-$ ( ) depende das cargas dos íons.

E - ( ) depende da concentração do eletrólito.

Figura 1. Imagem referente ao sistema com condutividade eletrolítica para ser associada a uma alternativa pelos estudantes

Cerca de $35 \%$ dos alunos afirmaram que apenas o sistema B da Figura 1 é representativo da condutividade em uma solução iônica, ou seja, os estudantes compreendem que quando os íons estão em meio aquoso, elétrons livres irão fechar o circuito, ao invés dos íons hidratados. Outra parte significativa dos alunos (15\%) concluiu que ambos os sistemas representam corretamente uma solução eletrolítica. Assim, metade dos estudantes considera que existem elétrons livres em uma solução eletrolítica.

Os alunos do curso de Bacharelado apresentaram $28 \%$ de acertos e os de Licenciatura $61 \%$. É preciso destacar que existem muitos formandos dos cursos de Química que não elaboraram modelos mentais adequados sobre o conceito de solução eletrolítica. É importante salientar que a literatura aponta que em pesquisas sobre modelos mentais, surgem modelos incompletos, equivocados e ambíguos, ${ }^{12}$ como foi observado para o tema de condutividade em solução iônica.

Sobre o conceito de equilíbrio químico, os alunos em geral apresentaram dificuldades em elaborar um modelo mental adequado. Apenas $42 \%$ dos estudantes estabeleceram uma relação adequada entre o conceito e a imagem apresentada. A Figura 2 apresenta a questão e a ilustração empregada.

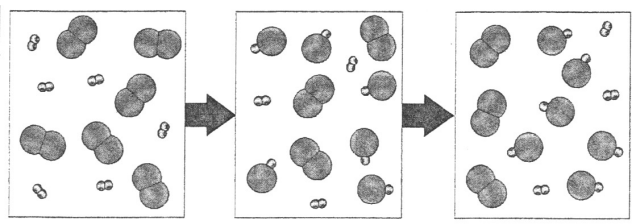

5) As figuras acima podem ser representativas de: A - ( ) uma reação ácido-base.

B - ( ) uma diminuição na pressão de um gás.

$\mathrm{C}$ - ( ) um equilíbrio químico do ácido iodídrico.

$\mathrm{D}$ - ( ) processo de ionização de um ácido forte.

$\mathrm{E}$ - ( ) uma reação de oxidação do gás iodo.

Figura 2. Imagem referente ao equilíbrio químico do HI para ser associada a uma alternativa pelos estudantes 
Do total de alunos, $28 \%$ afirmaram que a Figura 2 se refere a uma reação de oxidação do gás iodo e $14 \%$ associaram a imagem ao conceito de reação ácido-base. Muitos estudantes não estabeleceram relações adequadas entre a imagem e o conceito, ou seja, não apresentaram modelos mentais adequados sobre o conceito de equilíbrio químico. Além disso, mostraram que não possuem domínio sobre o conceito de oxidação e de reação ácido-base, pois associaram de modo inadequado estes conceitos com a imagem apresentada. Neste caso, os estudantes também apresentaram dificuldades em elaborar modelos temporais adequados sobre este conceito.

Os formandos dos cursos de Bacharelado e Licenciatura apresentaram um desempenho fraco nesta questão, com 39 e $46 \%$ de acertos, respectivamente. É preocupante que os formandos dos cursos de Química apresentem dificuldades em elaborar modelos mentais sobre o conceito de equilíbrio químico, que é abordado em muitas disciplinas dos cursos de graduação em Química.

Sobre a primeira lei da Termodinâmica, os alunos em geral apresentaram baixo índice de acertos, pois apenas $49 \%$ acertaram a questão. As turmas que apresentaram os melhores desempenhos foram o $2^{\circ}$ e o $4^{\circ}$ ano do curso de Licenciatura, com 60 e $67 \%$ de acertos, respectivamente. A Figura 3 apresenta a imagem utilizada na questão.

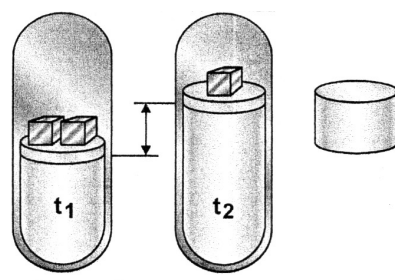

9) A figura acima pode ser representativa de:

$\mathrm{A}$ - ( ) equilíbrio químico na reação de decomposição do

$\mathrm{N}_{2} \mathrm{O}_{4}$.

$\mathrm{B}$ - ( ) processo de produção de gelo seco.

$\mathrm{C}$ - ( ) amostras de gás dentro e fora da geladeira..

D - ( ) um sistema para estudo da velocidade de reações.

$\mathrm{E}$ - ( ) $1^{\mathrm{a}}$ Lei da termodinâmica.

Figura 3. Imagem referente ao conceito da $1^{a}$ lei da Termodinâmica na questão do teste

Dentre os alunos que erraram a questão, $60,9 \%$ concluíram que a Figura 3 representa um sistema para estudo da velocidade de reações. É interessante notar que em todas as turmas, esta resposta é a de maior frequência dentre as incorretas. Cabe salientar também que os formandos dos cursos de Bacharelado e de Licenciatura apresentaram baixos índices de acerto, com 33 e 38\%, respectivamente. Novamente foram observados modelos incoerentes e problemáticos, conforme aponta a literatura ${ }^{12}$ sobre pesquisas realizadas com modelos mentais.

Em relação ao conceito de choques efetivos para ocorrência de reação química, houve um aumento gradual do desempenho dos alunos do curso de Licenciatura, ao contrário os formandos do curso de Bacharelado que tiveram um desempenho fraco para este conceito, com $11 \%$ de acertos. Em geral, apenas $37 \%$ dos estudantes estabeleceram a relação adequada entre o conceito e a imagem, apresentada na Figura 4.

Foi observado que $18 \%$ dos estudantes associaram a Figura 4 a etapas de uma reação SN2 entre oxigênio e clorometano e 34\% do total de alunos associaram essa figura com diferentes interações entre grupos eletrofílicos e nucleofílicos.

É importante salientar que houve discrepância entre os desempenhos dos formandos. Os formandos do curso de Bacharelado apresentaram $11 \%$ de acerto para esta questão e os do curso de Licenciatura $69 \%$. A literatura propõe que é normal encontrar modelos incoerentes, incompletos e inadequados em pesquisas sobre modelos mentais, ${ }^{12}$ entretanto, é preocupante que alunos formandos de cursos
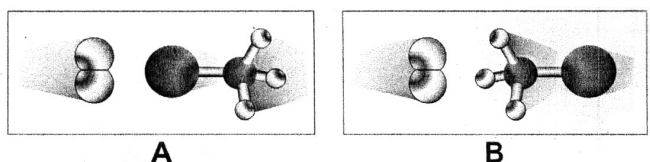

12) As figuras acima podem ser representativas de: $A$ - ( ) etapas de uma reação SN2 entre oxigênio e clorometano.

$\mathrm{B}$ - ( ) mistura de gases a diferentes temperaturas.

$\mathrm{C}$ - ( ) choques de moléculas com orientações inadequadas e adequadas, respectivamente, para a ocorrência da reação.

$\mathrm{D}$ - ( ) reação de hidrogenação de organoclorado.

$\mathrm{E}$ - ( ) diferentes interações entre grupos eletrofílicos e nucleofilicos.

Figura 4. Imagem referente ao conceito de choques efetivos e não efetivos para a ocorrência de reação química presente na questão

de Química não apresentem modelos mentais adequados também sobre este conceito, que é fundamental para a compreensão de vários outros conceitos químicos.

Dessa forma, é relevante observar que uma quantidade significativa de graduandos dos cursos de formação inicial em Química não consegue estabelecer associações adequadas entre estes conceitos químicos e imagens. Portanto, pode-se notar que existe um problema na formação inicial dos profissionais da Química, tanto nos cursos de Bacharelado como nos de Licenciatura em relação ao conhecimento químico. Aparentemente, uma parte significativa dos estudantes apresentou modelos mentais que contêm erros conceituais graves. Muitos alunos não sabem fazer representações submicroscópicas adequadas e/ou não sabem estabelecer a relação correta entre uma representação submicroscópica e um conceito químico.

Além disso, este problema pode ocorrer também na pós-graduação. É possível observar na literatura que estudantes de pós-graduação em Química apresentam modelos mentais semelhantes aos de alunos do Ensino Médio, ${ }^{17,31}$ conforme pode ser observado nas Figuras 5 e 6. Os estudantes apresentaram um modelo mental sobre a dissolução de cloreto de sódio em que ocorre a separação dos íons e, em seguida, os íons são atraídos pela água, considerando a polaridade da água e as cargas dos íons.

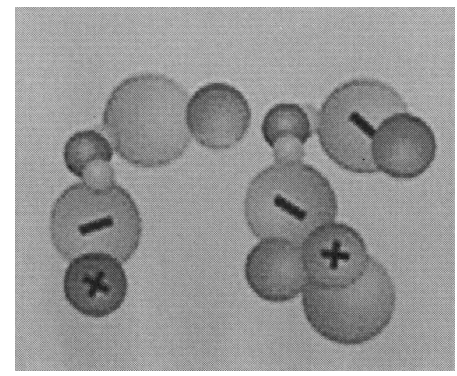

Figura 5. Representação da dissolução do cloreto de sódio em água por alunos da primeira série do Ensino Médio ${ }^{17}$

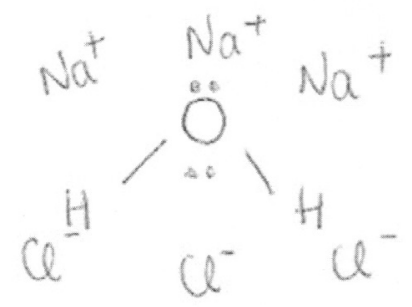

Figura 6. Representação da dissolução do cloreto de sódio em água por alunos pós-graduandos em Química ${ }^{3 l}$ 
As dificuldades observadas se devem basicamente ao fato de ser muito valorizado nos cursos de graduação o nível simbólico do conhecimento químico, essencialmente em aulas teóricas e o nível macroscópico, praticamente restrito às aulas experimentais, em detrimento do nível submicroscópico. Portanto, é importante que os formadores reflitam sobre as dificuldades conceituais dos estudantes e incorporem o uso da representação submicroscópica em sua prática pedagógica.

Outro ponto digno de nota é a alta carga horária de disciplinas de Química para o curso de Bacharelado. Este pode ter sido um fator que causou o baixo desempenho dos estudantes em várias questões. A diferença de aproveitamento detectada neste trabalho não corrobora concepções idiossincráticas comuns entre formadores universitários de que deficiências conceituais são sanadas com o aumento na quantidade de conceitos químicos e, consequentemente, de carga horária, trabalhados nos cursos.

\section{CONSIDERAÇÕES FINAIS}

Em geral, foi observado que os estudantes de Química apresentam dificuldades em alguns conceitos químicos importantes. Para os conceitos de precisão e exatidão em uma análise química, catálise heterogênea e choques de moléculas com orientação inadequada e adequada para a ocorrência da reação ocorreu uma melhora no desempenho dos alunos do curso de Licenciatura, na medida em que avançam no curso. Em contrapartida, foi observada uma diminuição no desempenho destes alunos para os conceitos de combustão, equilíbrio químico, isomeria espacial, condutividade de uma solução, a $1^{\text {a }}$ lei da termodinâmica e a estrutura de uma proteína com suas interações.

Comparando-se as turmas de formandos dos cursos de Licenciatura e Bacharelado, o desempenho foi muito parecido em muitos conceitos, como interações intermoleculares, precisão e exatidão em uma análise química, ionização de um ácido, $1^{a}$ lei da termodinâmica e modelo de reação enzimática. Os formandos do curso de Bacharelado apresentaram um desempenho superior ao dos formandos da Licenciatura para o tema química dos complexos de coordenação. Por outro lado, os formandos do curso de Licenciatura tiveram desempenho superior nos seguintes assuntos: combustão completa, isomeria espacial, condutividade de soluções eletrolíticas, entropia, catálise heterogênea, choques de moléculas com orientação inadequada e adequada para a ocorrência da reação, estrutura de uma proteína e suas interações moleculares.

Em geral, os modelos mentais apresentados por todos os graduandos possuem problemas e muitas vezes são semelhantes aos de alunos do Ensino Médio. ${ }^{32}$ Esta situação é alarmante e é um indício de que existem problemas na formação inicial em Química e, assim, cabe aos professores refletir sobre sua prática e a metodologia empregada nas práticas pedagógicas e implementarem inovações que considerem a formação de modelos mentais coerentes com as teorias científicas, inclusive com a valorização de imagens representativas dos fenômenos no nível submicroscópico. Isto pode ser realizado por meio do uso de experimentos e de animações, vídeos ou imagens estáticas que apresentem representações em nível submicroscópico.

Assim, o modelo de ensino adotado pelas instituições de ensino superior se mostra falho em um ponto fundamental: muitos alunos apresentam sérias dificuldades conceituais, dificuldades na elaboração de modelos mentais sobre conceitos químicos, ou seja, não aprenderam ou não sabem representar o conhecimento químico abordado durante o curso de graduação.

\section{MATERIAL SUPLEMENTAR}

O material suplementar, descrito a seguir, está disponível gratuitamente em http://www.quimicanova.sbq.org.br na forma de arquivo PDF, com acesso livre: Figura 1S. Representação da sequência de dissolução do cloreto de sódio em água por alunos da primeira série do Ensino Médio. ${ }^{17}$

\section{REFERÊNCIAS}

1. http://www.planalto.gov.br/ccivil_03/Leis/L9394.htm, acessada em Junho 2009 e Julho 2010.

2. Schnetzler, R. P.; Aragão, R. M. R.; Química Nova na Escola 1995, ${ }^{\circ}$ $1,27$.

3. Driver, R.; Asoko, H.; Leach, J.; Mortimer, E.; Scott, P.; Química Nova na Escola 1999, ${ }^{\circ} 9,31$.

4. http://portal.mec.gov.br/sesu/arquivos/pdf/130301Quimica.pdf, acessada em Junho 2009 e Julho 2010

5. Zucco, C.; Pessine, F. B. T.; de Andrade, J. B.; Quim. Nova 1999, 22, 454.

6. Faljoni-Alario, A.; Rossi, A. V.; Jorge, R. A.; Silva, A. B. F.; Oliveira, J. E.; Ferreira, L. H.; Rodrigues, R. M. B.; Quim. Nova 1998, 21, 674.

7. Zucco, C.; Quim. Nova 2007, 30, 1429.

8. Ferreira, P. F. M.; Justi, R. S.; Química Nova na Escola 1995, n 2, 32.

9. Kuhn, T. S.; A estrutura das revoluções científicas, $9^{\mathrm{a}}$ ed., Perspectiva: São Paulo, 2007.

10. Johnson-Laird, P. N.; Mental models: towards a cognitive science of language, inference, and consciousness, $1^{\text {st }}$ ed., Harvard University Press: Cambridge, 1983.

11. Borges, A. T.; Investigações em Ensino de Ciências 1997, 2, 207.

12. Norman, D. A.; In Mental Models; Gentner, D.; Stevens, A. L.; orgs; Lawrence Erlbaum Associates: Hillsdale, NJ, 1983.

13. Ontoria, A.; Luque, A.; Goméz, L. P. R.; Aprender com mapas mentais uma estratégia para pensar e estudar, $1^{\mathrm{a}}$ ed., Madras: São Paulo, 2008.

14. Johnstone, A. H.; J. Chem. Educ. 1993, 70, 701.

15. Johnstone, A. H.; University Chemistry Education 2000, 4, 34.

16. Wu, H. K.; Krajcik, J. S.; Soloway, E.; Journal of Research in Science Teaching 2001, 38, 821.

17. Gibin, G. B.; Dissertação de Mestrado, Universidade Federal de São Carlos, Brasil, 2009.

18. Ben-Zvi, R.; Eylon, B.; Silberstein, J.; Education in Chemistry 1987, 17, 117.

19. Gillespie, R. G.; J. Chem. Educ. 1997, 74, 484.

20. Dori, Y. J.; Barak, M.; Educational Technology \& Society 2001, 4, 61.

21. Oblinger, D. G.; Information Technology and Libraries 1993, 12, 246

22. Nakhleh, M. B.; J. Chem. Educ. 1993, 70, 52.

23. Nakhleh, M.; Mitchell, R. C.; J. Chem. Educ. 1993, 70, 190.

24. Paselk, R. J.; J. Chem. Educ. 1994, 71, 225.

25. Perales, F. J.; Jiménez, J. D.; Enseñanza de las Ciencias 2002, 20, 369.

26. Turner, K. E.; J. Chem. Educ. 1990, 67, 954.

27. Moran, J. M.; Tecnologia Educacional 1993, 22, 28.

28. Velázquez-Marcano, A.; Williamson, V. M.; Ashkenazi, G.; Tasker, R.; Williamson, K. C.; Journal of Science Education Technology 2004, 13, 313.

29. Russel, J. W.; Kosma, R. B.; Jones, T.; Wykoff, J.; Marx, N.; Davis, J.; J. Chem. Educ. 1997, 74, 330.

30. Nardi, R.; Longuini, M. D. Em Pesquisas em ensino de ciências; Nardi, R.; Bastos, F.; Diniz, R. E. S., orgs.; Escrituras: São Paulo, 2004.

31. Souza, K. A. F. D.; Cardoso, A. A.; Quim. Nova 2009, 32, 237.

32. Gibin, B. G.; Ferreira, L. H.; Anais do V Evento de Ensino de Química, Araraquara, Brasil, 2007. 


\section{A FORMAÇÃO INICIAL EM QUÍMICA BASEADA EM CONCEITOS REPRESENTADOS POR MEIO DE MODELOS MENTAIS}

Gustavo Bizarria Gibin* e Luiz Henrique Ferreira

Departamento de Química, Universidade Federal de São Carlos, CP 676, 13560-970 São Carlos - SP, Brasil
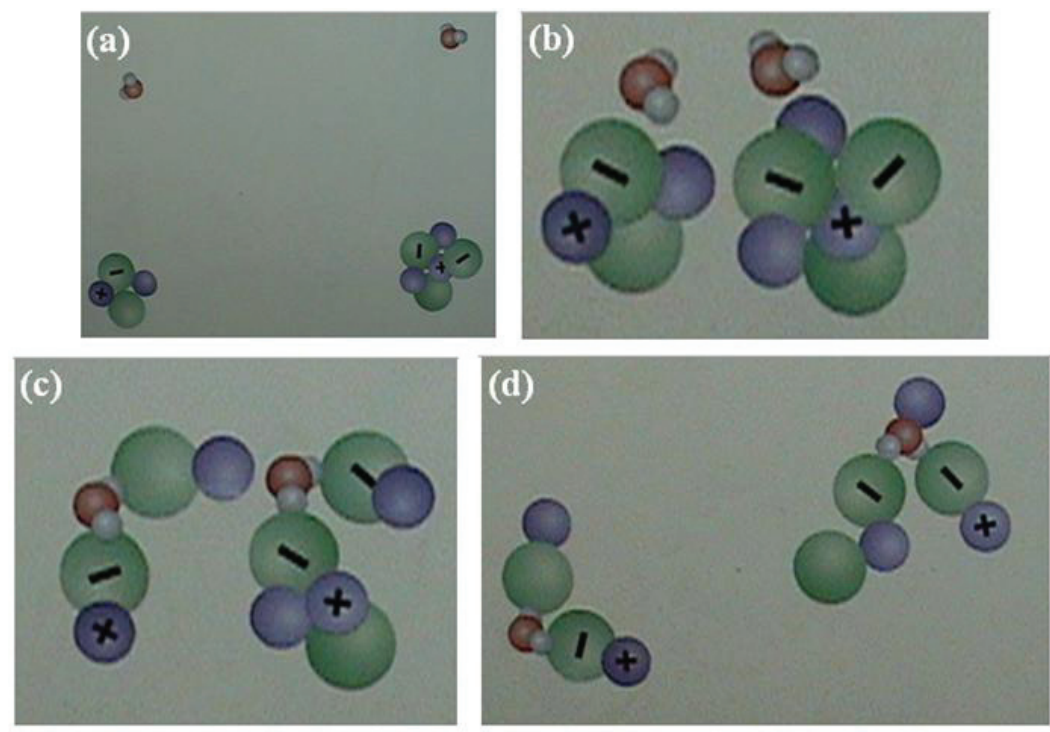

Figura 1S. Representação da sequência de dissolução do cloreto de sódio em água por alunos da primeira série do Ensino Médio ${ }^{17}$ 